\title{
Evolving concepts in disseminating medical science and the challenge of COVID-19
}

\author{
Annalisa Angelini, ${ }^{1}$ Mariavittoria Vescovo, ${ }^{2}$ Giorgio Vescovo ${ }^{3}$ \\ ${ }^{1}$ Full Professor of Pathology, Director PhD Course, Cardiovascular Pathology, Department of Cardiac, Thoracic and Vascular \\ Sciences and Public Health, University of Padua, Padua; ${ }^{2}$ Postgraduate Medical Student, Institute of Pathology, Department of \\ Radiological, Oncological and Anatomopathological Sciences, University La Sapienza Rome, Rome; ${ }^{3}$ Editor-in-Chief Italian \\ Journal of Medicine; Department of Internal Medicine, Azienda Ospedale-Università Padua, Padua, Italy
}

Spreading medical science to the scientific community is a must for benefitting the health of the world population. However, it represents, at the same time, an evolution in teaching, an improvement in research capability, and it promotes amelioration of experience and knowledge of doctors and scientists. When this is accomplished, our mission can be considered successful.

Publishing in scientific journals is one of the cornerstones of scientific dissemination, and it has been considered for a long time the far most penetrating way to reach the scientific world and allows researchers to progress. This concept a few years ago was resumed in the sentence publish or perish but the world has evolved and is offering us many more opportunities to communicate.

Peer review, online, open-access have been made available.

The last option requires paying a fee, which can be in most of the cases cumbersome and sometimes even too much for some researchers, and this can represent a discrimination drawback in science. Open access journals are a more democratic way to offer to everybody scientific information and knowledge.

Correspondence: Giorgio Vescovo, Department of Internal Medicine, Azienda Ospedale-Università Padua, Padua, Italy. E-mail: giorgio.vescovo@aopd.veneto.it

Key words: COVID-19; spreading medical science; open access; social media.

Received for publication: 2 September 2020. Accepted for publication: 2 September 2020.

This work is licensed under a Creative Commons Attribution NonCommercial 4.0 License (CC BY-NC 4.0).

${ }^{\circ}$ Copyright: the Author(s), 2020

Licensee PAGEPress, Italy

Italian Journal of Medicine 2020; 14:117-118

doi:10.4081/itjm.2020.1367
Social media have become available, and the current digital landscape encompasses Facebook, Twitter, LinkedIn, Instagram, Pinterest, YouTube, Apple Podcasts, Google Play, etc., making communication easy, immediate, and available to a broad audience mass.

The appearance of such systems has very often made dodgy the quality of data. The review process traditionally made by the authors-editor-reviewer-editor chain is broken. These data are spread on the media with a poor review, if any, offering the hip to malfeasance in medical research represented by fabrication, falsification, and plagiarism. A typical example of this being p-hacking, in other words, the manipulation of the source and the selection of data analysis that support the starting hypothesis employing data dredging, fishing, and butchery. All this, together with the intellectual and financial conflict of interest, the search of power, passing over ethical rules of conducting studies, mine the basic principles of research.

The purpose of this is publishing in predatory, even non-existing, low-quality journals for ensuring grants and careerism. A faster and more diffuse publication of data has become essential. This was an already ongoing process when suddenly the COVID-19 pandemic came across. The need to fill the gap in a field where almost nothing was known, has pushed the scientific world to a rush toward data publication.

During this pandemic, some journals have now opened a new way of quick reporting, which goes through the option of in-review system, which guarantees a quick but uncontrolled, not reviewed, attribution of a DOI and the possibility of free fruition of the study content by everybody free of charge, until the paper stays in the review system. With a DOI and the download option, it is possible to quote the study.

A tsunami of papers has flooded journals, review systems have sometimes collapsed, if not that was pricey and at both authors' and editors' expense. Data quality has proven to be very often low, and manuscripts just published are overtaken by some others 
with conflicting results. The door for low-quality papers or misconducted trials has been opened, and social media have played an essential role in doing so.

Meetings/Congresses have always been viewed as an important step in the spreading process of knowledge, since they allow discussion, confrontation, enlightening for new ideas.

Meetings have another benefit, which is represented by the networking with experts in the field, opening up new opportunities for collaborations. How many people have met their future mentors at congresses?

During the pandemic, we have moved from inpresence to virtual meetings, in the attempt of reversing the feeling that research could be stopped, and of continuing spreading science, presenting results, keeping personal contact, even virtual.

Was this a challenge or an opportunity for all of us?

After the first shock, when we thought that we could not cope without congresses, we realized that virtual congresses could represent a new way of spreading our research. For sure, online, we can present and guarantee dissemination of results, but discussion and rebuttal seem less effective. Less networking than in presence contacts, more difficulties in brainstorming between different groups.

Are we ready for considering the virtual congresses a permanent option for the future, regardless of the constriction of the pandemic? Can we foresee a hybrid model with few people attending in person and a larger audience online? Do we need to learn and to teach our students a different way of communication?

We all agree on the fact that the future envisages the involvement of social media, digital initiative, podcasts, and a dive in the digital world to engage the research community and embrace its interest, expand interaction, optimize operation, involve young investigators, but this needs some optimization in running scientific journals. The aforesaid includes the appointment of special media editors, transparent peer reviews, reviewers' comments, and authors' responses publishing online, online letters to editors, enhanced supplemented materials and metadata, display of row data, optimization of operation of digital platforms. However, the future of the digital world is risky to predict, depending on the evolution of media sites, the possible impact of living data sets, graphical data and holograms display, live streams with group discussion, and other options. The potential menaces represented by this evolving system can be, however, tackled by keeping in mind that journals and media should not represent a policing organization. Furthermore, dissemination of scientific information relies on a contract of honesty and transparency, together with ethics respect.

If COVID-19 has positively contributed to pushing forward this evolution, it will soon be evident. 